\title{
Analysis of some indicators by means of fuzzy logic on the example of Azerbaijani energy enterprises
}

\author{
Ulviyya Rzayeva ${ }^{1 *}$, Aida Guliyeva ${ }^{2}$, and Narmin Jafarova ${ }^{3}$ \\ ${ }^{1}$ Center of Digital Economy, Azerbaijan State University of Economics, 6, Istiglaliyyat str., AZ1001, \\ Baku, Azerbaijan \\ ${ }^{2}$ Department of Digital Technologies and Applied Informatics, Faculty of Digital Economy, Azerbaijan \\ State University of Economics, 6, Istiglaliyyat str., AZ1001, Baku, Azerbaijan \\ ${ }^{3}$ Moses Lab Marketing Agency, 156, Aynalı Plaza, Ahmed Rajabli str., Baku, Azerbaijan
}

\begin{abstract}
One of the most promising areas of scientific research in the field of analysis, forecasting and modelling of economic phenomena and processes is fuzzy logic. In the article with the use of the fuzzy logic apparatus (Fuzzy Logic toolkit of the MATLAB software package) a model for assessing the development of manufacturing indicators is developed. Key indicators for evaluating the activities of energy enterprises are analysed. The model is based on microeconomic indicators of the enterprises' efficiency and development. The presented indexes pass through the stage of fuzzification, at which each measure is assigned the membership function; then comes the decision stage; finally, the task ends by the stage of defuzzification, i.e., bringing the resulting fuzzy value to precise ones. The application of the Mamdani fuzzy inference algorithm allows getting an exact value of the consolidated indicator of enterprise development. The resulting value allows making operational management decisions in the energy enterprises in real-time.
\end{abstract}

\section{Introduction}

For the country's production potential, the efficiency of enterprises and their development act as the most important means of achieving national economic goals and interests. Azerbaijani manufacturing sector unites enterprises whose economic activity consists of the creation and processing of mostly petroleum products. This sector is of paramount importance in calculating GDP since its existence enables national economies to gain competitive advantages and enter the global trading environment. The article discusses how the effectiveness of this industry can be achieved by accelerating trade relations, as well as increasing the competitive advantages - with the help of technological advances, and improving the security of any type of assets - taking into account possible threats. The role of these indicators in assessing the development of manufacturing enterprises - trade, innovation and technology, and security - is the focus of this work. The resulting assessment

\footnotetext{
*Corresponding author: ulviyya.rzayeva@unec.edu.az
} 
is necessary to identify strengths and weaknesses, but the lack of clear, quantitative values in the development concept can lead to incorrect results [1]. The fuzzy logic approach used, in which even ambiguity matters, has helped to obtain more adequate results.

Considering the role of consolidated indicators in the development of energy enterprises, it should be assumed that they perform the functions of providing information on the current level of growth and effectiveness of activities for a certain period to local and foreign investors. The role of consolidated information in the implementation of such functions will be determined by the needs of a particular manufacturer. Moreover, various groups of manufacturers are interested in different information: owners - in financial results and financial stability, investors and lenders - in creditworthiness, managers - in all aspects of the enterprise.

In the context of the formation of fundamentally new requirements for the informatization of society on the activities of the energy enterprises in Azerbaijan, the issues of development and implementation of an effective methodology for analysing consolidated quantitative information using new mathematical approaches (in particular, fuzzy) are relevant [2].

The article is structured as follows. The first section called methodology presents a set of goals, principles and the approaches used to create a logical organization of research. Section two reviews the related literature. The third section shows the scheme for constructing fuzzy rules, obtaining results with the use of MATLAB package and the built-in Fuzzy Logic Toolbox, as well as empirical results obtained by the described techniques. A discussion of the results and conclusion are featured in section four.

\section{Materials and methods}

Fuzzy logic, as its name indicates, is an alternative to classical logic, and allows us to quantify the uncertainty, variability, and inconsistency in the behaviour of economic systems. In the real world, especially in economics, there are many vague, inaccurate, uncertain, ambiguous knowledge. The main problem arises when these qualitative indicators need to be converted into quantitative ones. Such a tool for a more accurate reproduction of reality is the apparatus of fuzzy logic and fuzzy sets [3].

The article explores and analyses several indexes and their subindexes. Following them, we determine the input data and obtain the output variable using membership functions, which is the main tool of fuzzy logic. We used triangular fuzzy membership functions for both input and output data since they are more convenient for representing data in percent or proportions and their further processing [4]. The application of triangular functions leads to linear interpolation: possible phase transition construction based on triangular functions, gives an option of independent specification of the values of the reproduced function in the interpolation nodes. Therefore, this function type is used to determine appropriate scales and linguistic variables to the concrete valuation of both input and output variables [5].

When evaluating the relevant data on manufacturing enterprises, the fuzzy logic approach is more reliable, while a quantitative system does not give fuzzy concepts that are inherent for production economy. For the correct result, based on reliable indicators, a sufficient number of rules have been presented. The corresponding conclusion has been obtained by the MATLAB software. According to the study [6], using the Fuzzy Logic Toolbox GUI tools, a fuzzy output system can be created for any model.

The main goal of the work is to evaluate the activity of manufacturing enterprises in Azerbaijan based on consolidated indicators on trade, security, and innovation in energy enterprises. To solve this problem, a set of rules have been built that allow describing a set of fuzzy situations in the subject area and comparing them with each other.

As a result, rule tables have been built, which give us an opportunity to assess the current situation on the efficiency of the energy enterprises. The main advantage of this model is the 
establishment of fuzzy situations using linguistic variables. This makes it easy to understand the conditions under development and create a model for more complex situations. The Fuzzy Inference System (FIS) procedure is applied to quantify the qualitative levels of indicators, and based on the accepted criterion to find out the best alternatives for achieving our goal.

\section{Literature review}

Fuzzy logic is widely used in socio-economic researches: assessing the development of economic sectors, insurance, supporting decision-making, modelling the economies of regions and countries, forecasting, etc.

A review of the literature justifies the use of fuzzy logic to evaluate economic indicators, perform environmental, medical, engineering and other problems. Fuzzy logic methods allow the analysis of indicators of the object under uncertain conditions, for example, in cases where there is no any fully-fledged statistics, or qualitative data should be included among the studied indicators.

The MATLAB software package, containing the Simulink with Fuzzy Toolbox visual modelling tool, allows developing fuzzy models, evaluating their characteristics and graphically presenting the results.

Zlateva et al. in [7] presents a model of fuzzy inference for a comprehensive assessment of natural hazards in the southwestern region of Bulgaria, solving the multicriteria problem by the MATLAB software environment and the built-in Fuzzy Logic Toolbox package are used. An information system for disaster risk management is being developed, and the developed fuzzy system is presented as its integrated part.

The study [8] analyses the correlation between class attendance and student performance using fuzzy logic methods. The work is based on data from 330 students. Fourteen membership functions of fuzzy logic were used; implementation is carried out using the MATLAB Fuzzy Toolbox.

The aim of the study [9] is to develop an expert system using multiple FIS to predict daily trading performance. The authors argue that the developed model shows better results compared to the existing model with a similar goal.

The article [10] presents an approach that provides multi-purpose optimization of performance indicators of small and medium enterprises (SMEs). Value optimization was tested on a group of 197 SMEs; the results were obtained based on the fuzzy set approach.

Based on fuzzy rules the investigation [11] presents the development of a technical indicator for stock and currency markets when deciding on the securities' purchase and sale. As linguistic variables, the generalized volumes of the securities' purchase and sale, and their generalized prices are used.

The study [12] describes the experimental project of fuzzy controlling the fluid flow process. The simulation results clearly show that the intelligent fuzzy logic controller provides optimal control without increasing the fluid flow rate compared to the conventional PID (Proportional Integral Derivative) - controller.

One of the important areas of constructing an application with the fuzzy approach is the design of a fuzzy control system. In preparing a framework concept, an important step and a necessary guarantee is a system simulation. Article [13] describes methods of overcoming the working inconveniences that traditionally arise during simulations using fuzzy logic toolkits and the SILMULINK package.

The article [14] is devoted to simulation of fuzzy traffic control of traffic flow at a multiline roundabout. The smart controller runs the waiting time and the queue length of vehicles in proportion to the length corresponding to the green and other phases. The management strategy provides for smooth traffic flow with minimal latency and queue length. 
Zurek in [15] devotes his research in the medical field to the results of the implementation of a fuzzy inference system for the identification of four over-the-counter drugs.

The study [16] describes the automatic control of engine speed with switchable resistance using PID. The operation of the proportional-integral controller is simulated on a separate computer using the MATLAB/Simulink software. The fuzzy PID algorithm is compared with the conventional PID algorithm. The authors insist that using the proposed method, the engine reaches the reference speed in less time.

Thus, complex-structured systems operating under conditions of significant uncertainty, when applying the apparatus of the theory of fuzzy sets, give better results than when using known statistical or economic-mathematical models.

\section{Empirical model}

In this research paper, the main three microeconomic indicators of energy manufacturing enterprises were analysed to assess the efficiency level of the development of this kind of business. The actuality and importance of the indicators for both the national economy and the abovementioned industry type, particularly, are discussed as follows:

First, trade enables specialization and large-scale operation, provides access to technology and learning, offers increased competition, and increases the value of a country's natural resources. National trade is necessary to keep money in circulation within a country, which improves the economy and the living standards of its citizens. Likewise, trade between regions fosters equitable development, cultural, technical exchange and investments throughout the country. International trade, also known as foreign trade, is the one that encompasses the purchase and sale of goods and services between different countries and their markets. However, today we can no longer talk only about strictly business relationships. New technologies have globalized the planet, and cultural and political relations have also reached a world level. In this context, trade relations within and outside countries have gained significance in the energy manufacturing industry since it helps to use the benefits of value creation, gain competitive advantage and go globally easier and more beneficial than previous times.

Second, the possibility of competing products entering the energy market stimulates innovation activities and particularly encourages the invention of Innovations and New Technologies. When it comes to processes, which are an inseparable component of innovation in the energy manufacturing industry, companies are eager to invest in sectors where production technologies are changing rapidly. Judiciously designed competition policy in energetics contributes to innovation by facilitating the arrival of competing products, as well as by promoting the introduction of new technologies.

Moreover, referring to the functioning of processes of energy industry participants, safety and security can be defined as the ability of a system to operate while controlling the risks to people, property and environment at an acceptable level.

Undoubtedly, security is closely related to the economy. In particular, crime and violence can inhibit the production of goods and services, thus constituting a serious impediment to greater economic vigour. Insecurity affects countries both enterprise and macroeconomic level. It dampens the ability to empower performance, as well as, negatively affects reputation, since reputation directly affects the number of foreign investments. It can be sure that it has a great emphasis on economic dynamism. Therefore, a favourable environment of tranquillity and public peace in industries is justified by the potential to increase sustained economic growth. 


\subsection{Trade}

Throughout time, the main goal of enterprises was to maximize profits, while the trade acts as the most important and necessary condition without which this goal cannot be achieved. The paper presents the following subindexes of energy trade:

- Energy export in the trade performance, since the indicator of trade in manufacturing enterprises, is more dependent on fluctuations in the value of direct or indirect exports [17];

- Direct energy export in the trade performance, as the motivational mechanism for the development of production enterprises, is based on the comparative advantages that companies can obtain by direct export of manufactured products [18];

- The energy sales, since the prospects for direct exports specifically depend on the target sales markets, without applying to market channels [19];

- Production dependence on imports. This indicator is used to analyse the dependence of production enterprises on the import of intermediate goods for energy manufacturing [20];

- The share of total inputs used in the production which comes from the domestic origin resources; if the economy and enterprises can be self-sufficient for further manufacturing processes, it can gain competitive advantages in nearly all situations [21].

The first step of the model construction is the fuzzification of our input variables. As their membership function, we use a triangular function. For the first term _Trade_, we took six input variables according to the number of our subindexes:

Input 1 . The proportion of energy enterprises engaged in export directly or indirectly (Minimum $10 \%$ of their sales);

Input 2. The proportion of energy enterprises engaged in export directly (Minimum 10\% of their sales);

Input 3. Share of total sales engaged in export directly;

Input 4. The proportion of enterprises, which use foreign material inputs or supplies;

Input 5. The degree of total inputs that imported or has a foreign origin (\%);

Input 6 . The degree of total inputs produced completely in the domestic market (\%).

Each input variable has five triangular membership functions. A linguistic expression for a fuzzy set of input variables is shown in Table 1:

Table 1. Fuzzy set of input variable of the term _Trade

\begin{tabular}{|l|l|l|}
\hline Range & Interval & Linguistic Variable \\
\hline 0 to 25 & $(0,0,25)$ & Poor \\
\hline 0 to 50 & $(0,25,50)$ & Fair \\
\hline 25 to 75 & $(25,50,75)$ & Average \\
\hline 50 to 100 & $(50,75,100)$ & Good \\
\hline 75 to 100 & $(75,100,100)$ & Excellent \\
\hline
\end{tabular}

The membership function of our output variable is a triangular. We will present it not in tabular but in graphical form (Figure 1), taken from the MATLAB editor: 


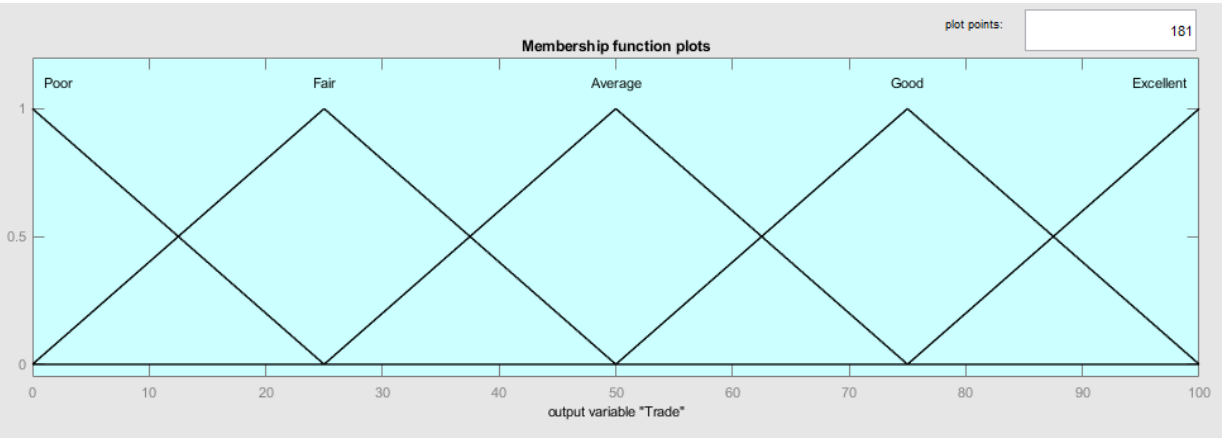

Fig. 1. The membership function of the output variable of the term _Trade

The next step in our modelling is the inference procedure according to the IF-THEN rules. Our combination of rules is as follows:

1) If (Proportion of enterprises engaged in export directly or indirectly is Poor) then (Trade is Poor);

2) If (Proportion of enterprises engaged in export directly or indirectly is Fair) then (Trade is Fair);

3) If (Proportion of enterprises engaged in export directly or indirectly is Average) then (Trade is Average);

4) If (Proportion of enterprises engaged in export directly or indirectly is Good) then (Trade is Good);

5) If (Proportion of enterprises engaged in export directly or indirectly is Excellent) then (Trade is Excellent);

6) If (Proportion of enterprises engaged in export directly is Poor) then (Trade is Poor);

7) If (Proportion of enterprises engaged in export directly is Fair) then (Trade is Fair);

8) If (Proportion of enterprises engaged in export directly is Average) then (Trade is Average);

9) If (Proportion of enterprises engaged in export directly is Good) then (Trade is Good);

10) If (Proportion of enterprises engaged in export directly is Excellent) then (Trade is Excellent);

11) If (Share of total sales engaged in export directly is Poor) then (Trade is Poor);

12) If (Share of total sales engaged in export directly is Fair) then (Trade is Fair);

13) If (Share of total sales engaged in export directly is Average) then (Trade is Average);

14) If (Share of total sales engaged in export directly is Good) then (Trade is Good);

15) If (Share of total sales engaged in export directly is Excellent) then (Trade is Excellent);

16) If (Proportion of enterprises engaged in export directly is Poor) and (Proportion of enterprises, which use foreign material inputs or supplies is Poor) then (Trade is Poor);

17) If (Proportion of enterprises engaged in export directly is Fair) and (Proportion of enterprises, which use foreign material inputs or supplies is Fair) then (Trade is Fair);

18) If (Proportion of enterprises engaged in export directly is Average) and (Proportion of enterprises, which use foreign material inputs or supplies is Average) then (Trade is Average);

19) If (Proportion of enterprises engaged in export directly is Good) and (Proportion of enterprises, which use foreign material inputs or supplies is Good) then (Trade is Good);

20) If (Proportion of enterprises engaged in export directly is Excellent) and (Proportion of enterprises, which use foreign material inputs or supplies is Excellent) then (Trade is Excellent) 
21) If (Share of total sales engaged in export directly is Poor) and (The degree of total inputs that imported or has foreign origin is Poor) then (Trade is Poor);

22) If (Share of total sales engaged in export directly is Fair) and (The degree of total inputs that imported or has foreign origin is Fair) then (Trade is Fair);

23) If (Share of total sales engaged in export directly is Average) and (The degree of total inputs that imported or has foreign origin is Average) then (Trade is Average);

24) If (Share of total sales engaged in export directly is Good) and (The degree of total inputs that imported or has foreign origin is Good) then (Trade is Good);

25) If (Share of total sales engaged in export directly is Excellent) and (The degree of total inputs that imported or has foreign origin is Excellent) then (Trade is Excellent);

26) If (Share of total sales engaged in export directly is Poor) and (The degree of total inputs produced completely in the domestic market is Poor) then (Trade is Poor);

27) If (Share of total sales engaged in export directly is Fair) and (The degree of total inputs produced completely in the domestic market is Fair) then (Trade is Fair);

28) If (Share of total sales engaged in export directly is Average) and (The degree of total inputs produced completely in the domestic market is Average) then (Trade is Average);

29) If (Share of total sales engaged in export directly is Good) and (The degree of total inputs produced completely in the domestic market is Good) then (Trade is Good);

30) If (Share of total sales engaged in export directly is Excellent) and (The degree of total inputs produced completely in the domestic market is Excellent) then (Trade is Excellent);

Our output function will be determined according to the minimax principle [22]. The results of our calculations, according to which the output variable is equal to 15.8 (shows the level of "poor") are presented in the Figure 2:

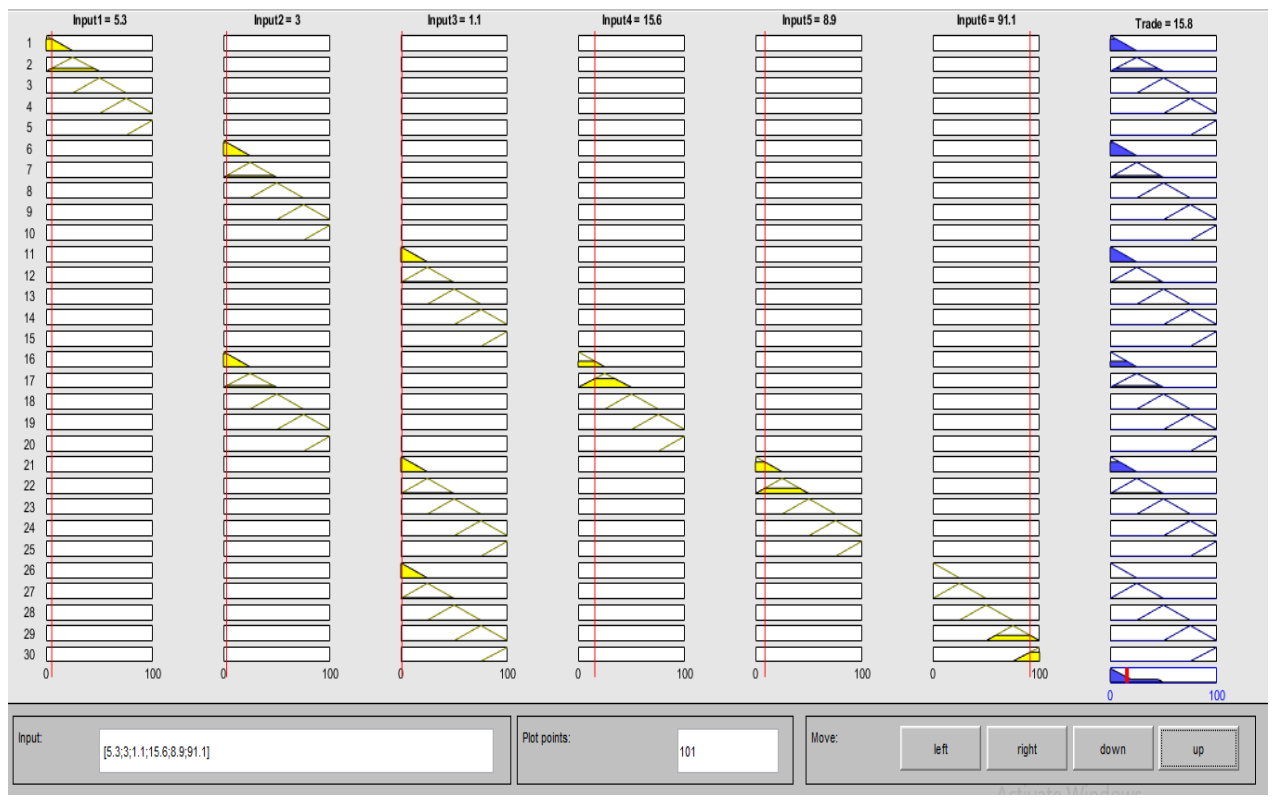

Fig. 2. The result calculations for term _Trade_ 


\subsection{Innovation \& technology}

Over the past decades, interest in innovation among scientists and economists has increased significantly, which is natural, since innovation has become one of the main irreplaceable components of economic growth. Innovations are a prerequisite for the development of production, improving the quality and increasing the variety of products and services, and both in developing and developed market economies, they are the driving force of competition; thanks to them they can use modern technology and organization of production, to ensure the success and effectiveness of the enterprises. Therefore, the following subindexes are included in the paper:

- Licensed and imported technology holders from foreign companies. This subindex indicates on the importance in solving the strategic problems of energy enterprises entering the international market, increasing competitiveness and economic efficiency as well as presents how licensing promotes innovation [23].

- Enterprises, which has their website platform. As a rule, the establishment of websites for commercial organizations is significant. Its specific functions-image, information, advertising serves to increase its commercial function, which is considered to be positively related to the improvements of the enterprise and its technological environment [24].

- Energy enterprises, which launched a new product or service, as an introduction of a new product is a basis for business development and innovation management [25].

- Innovation methods in enterprises. Firms put a process innovation method into operation because they ensure a qualitative increase in the efficiency of processes or production of goods that are in demand by the market and has a great impact also on accelerating economies of scale [26].

- Enterprises that invest on Research and Development, whereas R\&D is the most important task of the "knowledge economy". It also helps to increase the pace of development of the energy manufacturing sector of the economy, the transition from uncontrolled economic growth to sustainable development [27].

- Holder firms of international quality certificates. Whereas special attention needed to pay to the analysis of problems of international standardization and technical regulation of national production, this kind of measures are necessary for the implementation and further improvement of the process of normative and technical regulation of the international economy [28].

The first step of the model construction is putting our input variables into the Fuzzy Logic Designer. We need to use a triangular function for their membership functions. For our output variable of the term Innovation and Technology_, we took 7 input variables due to the number of our subindexes:

Input 1. The proportion of enterprises, which imported technologies from foreign companies;

Input 2. The proportion of enterprises, which has their Web site platform;

Input 3. The proportion of enterprises, which use business e-mails to communicate with customers and suppliers;

Input 4. The proportion of enterprises, which launched a new product or service;

Input 5. The proportion of enterprises, which put a process innovation method into operation;

Input 6. The proportion of enterprises, which invests on Research and Development (R\&D);

Input 7. The proportion of enterprises, which holds internationally-recognized certificates for quality. 
The next step in our modelling is the inference procedure according to the IF-THEN rules. Our combination of rules is as follows:

1) If (The proportion of enterprises, which imported technologies from foreign companies is Poor) and (The proportion of enterprises, which launched a new product or service is Poor) and (The proportion of enterprises, which put a process innovation method into operation is Poor) then (Innovation \& Technology is Poor);

2) If (The proportion of enterprises, which imported technologies from foreign companies is Fair) and (The proportion of enterprises, which launched a new product or service is Fair) and (The proportion of enterprises, which put a process innovation method into operation is Fair) then (Innovation \& Technology is Fair);

3) If (The proportion of enterprises, which imported technologies from foreign companies is Average) and (The proportion of enterprises, which launched a new product or service is Average) and (The proportion of enterprises, which put a process innovation method into operation is Average) then (Innovation \& Technology is Average);

4) If (The proportion of enterprises, which imported technologies from foreign companies is Good) and (The proportion of enterprises, which launched a new product or service is Good) and (The proportion of enterprises, which put a process innovation method into operation is Good) then (Innovation \& Technology is Good)

5) If (The proportion of enterprises, which imported technologies from foreign companies is Excellent) and (The proportion of enterprises, which launched a new product or service is Excellent) and (The proportion of enterprises, which put a process innovation method into operation is Excellent) then (Innovation \& Technology is Excellent);

6) If (The proportion of enterprises, which has their Web site platform is Poor) and (The proportion of enterprises, which use business e-mails to communicate with customers and suppliers is Poor) then (Innovation \& Technology is Poor);

7) If (The proportion of enterprises, which has their Web site platform is Fair) and (The proportion of enterprises, which use business e-mails to communicate with customers and suppliers is Fair) then (Innovation \& Technology is Fair)

8) If (The proportion of enterprises, which has their Web site platform is Average) and (The proportion of enterprises, which use business e-mails to communicate with customers and suppliers is Average) then (Innovation \& Technology is Average);

9) If (The proportion of enterprises which has their Web site platform is Good) and (The proportion of enterprises, which use business e-mails to communicate with customers and suppliers is Good) then (Innovation \& Technology is Good);

10) If (The proportion of enterprises which has their Web site platform is Excellent) and (The proportion of enterprises, which use business e-mails to communicate with customers and suppliers is Excellent) then (Innovation \& Technology is Excellent);

11) If (The proportion of enterprises, which launched a new product or service is Poor) and (The proportion of enterprises, which put a process innovation method into operation is Poor) then (Innovation \& Technology is Poor);

12) If (The proportion of enterprises, which launched a new product or service is Fair) and (The proportion of enterprises, which put a process innovation method into operation is Fair) then (Innovation \& Technology is Fair);

13) If(The proportion of enterprises, which launched a new product or service is Average) and (The proportion of enterprises, which put a process innovation method into operation is Average) then (Innovation \& Technology is Average);

14) If (The proportion of enterprises, which launched a new product or service is Good) and (The proportion of enterprises, which put a process innovation method into operation is Good) then (Innovation \& Technology is Good); 
15) If (The proportion of enterprises, which launched a new product or service is Excellent) and (The proportion of enterprises, which put a process innovation method into operation is Excellent) then (Innovation \& Technology is Excellent);

16) If (The proportion of enterprises, which invests on $R \& D$ is Poor) and (The proportion of enterprises, which holds internationally-recognized certificates for quality is Poor) then (Innovation \& Technology is Poor);

17) If (The proportion of enterprises, which invests on $R \& D$ is Fair) and (The proportion of enterprises, which holds internationally-recognized certificates for quality is Fair) then (Innovation \& Technology is Fair);

18) If (The proportion of enterprises, which invests on R\&D is Average) and (The proportion of enterprises, which holds internationally-recognized certificates for quality is Average) then (Innovation \& Technology is Average);

19) If (The proportion of enterprises, which invests on $R \& D$ is Good) and (The proportion of enterprises, which holds internationally-recognized certificates for quality is Good) then (Innovation \& Technology is Good);

20) If (The proportion of enterprises, which invests on R\&D is Excellent) and (The proportion of enterprises, which holds internationally-recognized certificates for quality is Excellent) then (Innovation \& Technology is Excellent);

Our output function will be determined according to the minimax principle. The results of our calculations, according to which the output variable is equal to 29 (shows the level of "fair") are presented in the Figure 3:

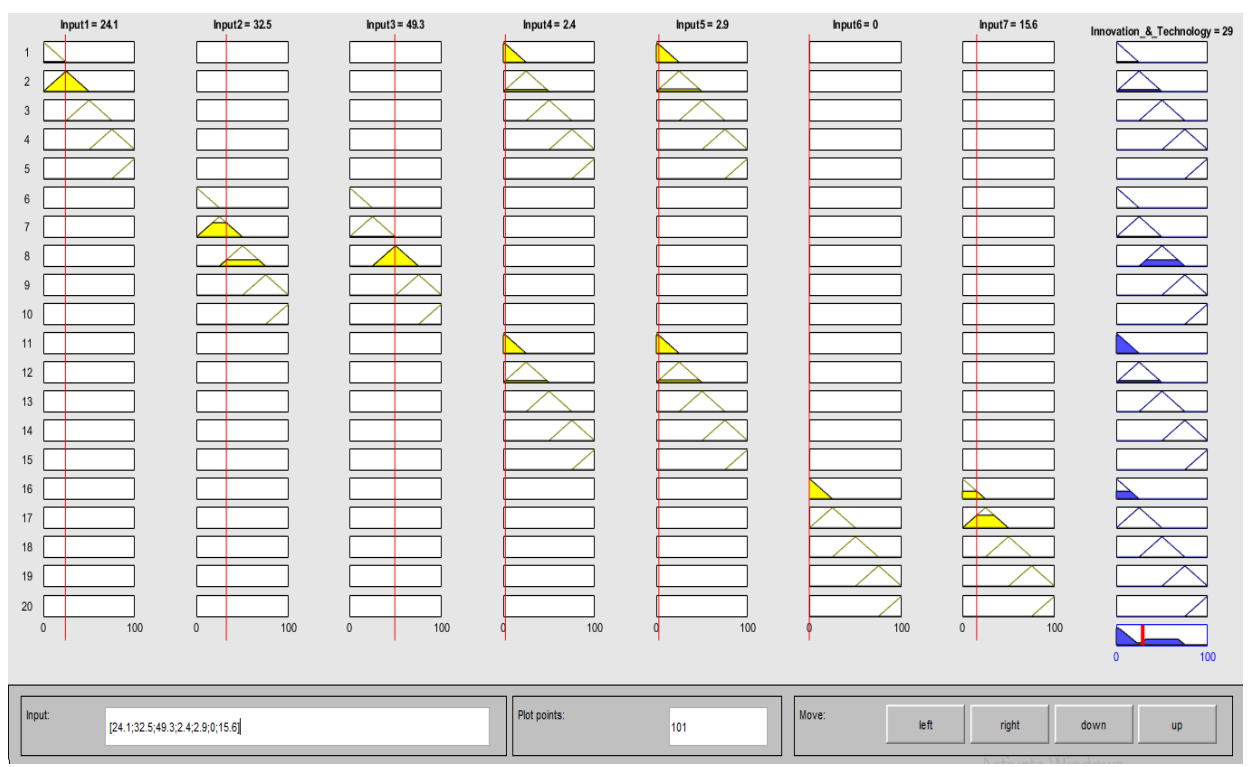

Fig. 3. The result calculations for term _Innovation and Technologies

\subsection{Security}

The external and internal environment of any enterprise always bears its unique features, opportunities, and threats related to the profile of activity, size of production, number of staff, geographical and regional features and other factors. An auxiliary function, designed to protect the enterprise from internal and external threats, is the security function. This function 
should be built on the principle of "a threat to security is primary for measures to protect the enterprise from threats" [29]. This principle exists to ensure that the enterprise's measures to protect it from real and potential threats that are dangerous and vital for the economic security of the businesses. Following other functions of the businesses, the security system must be adequate to threats and correspond to the financial capabilities of the enterprise.

- The proportion of enterprises making payments for security or protection issues. An analysis is made of the experience of market participants who take measures to determine necessary actions to minimize threats and participants, establish the reasons that prompted them to terminate their activities or simply take preventive or corrective measures against any kind of violence [30];

- Average security costs if the enterprises make payments for security or protection (estimated as the percentage of annual sales). A significant problem for the domestic enterprises is increasing the effectiveness of financial costs. The elimination of ineffective costs is needed to improve the process of managing innovation and production activities. Therefore, average security costs are worth to be assessed as an additional expense for enterprises [31];

- Average losses or any damages because of burglary (estimated as the percentage of annual sales). This subindex is needed to the accurate calculation of losses from theft and shortage which should begin with an acquaintance with the procedure for determining the amount of losses from theft, shortage, destruction of tangible or intangible assets, for instance, intellectual property as well as any cyber-attack cases [32];

- The proportion of total product value, which was lost when delivering to the domestic markets. There are many reasons: severe frosts, transport accidents, fires, theft, etc. However, theft as the reason for the spoilage or disappearance of the goods is the most difficult one to mitigate the risks completely for avoid additional costs and delay in shipping which can result in loss of customer value [33];

The first step of the model construction is putting our input variables into Fuzzy Logic Designer for fuzzification. We need to use a triangular function for their membership functions. For our output_Security_ we took 6 input variables due to the number of our subindexes:

Input 1. The proportion of enterprises making payments for security or protection issues;

Input 2. If the enterprises make payments for security or protection, average security costs (estimated as the percentage of annual sales);

Input 3. The proportion of enterprises has losses or any damages because of burglary;

Input 4. If the enterprises experience losses, average losses or any damages because of burglary (estimated as the percentage of annual sales);

Input 5 . The proportion of total product value, which was lost when delivered to domestic markets;

Input 6. The proportion of enterprises, which describes violence, theft, and other disorders as the main limitation.

The next step in our modelling is the inference procedure according to the IF-THEN rules. Our combination of rules is as follows:

1) If (The proportion of enterprises has losses or any damages because of burglary is Poor) and (The enterprises experience losses, average losses or any damages because of burglary is Poor) then (Security is Excellent);

2) If (The proportion of enterprises has losses or any damages because of burglary is Fair) and (The enterprises experience losses, average losses or any damages because of burglary is Fair) then (Security is Good);

3) If (The proportion of enterprises has losses or any damages because of burglary is Average) and (The enterprises experience losses, average losses or any damages because of burglary is Average) then (Security is Average); 
4) If (The proportion of enterprises has losses or any damages because of burglary is Good) and (The enterprises experience losses, average losses or any damages because of burglary is Good) then (Security is Fair);

5) If (The proportion of enterprises has losses or any damages because of burglary is Excellent) and (the enterprises experience losses, average losses or any damages because of burglary is Excellent) then (Security is Poor);

6) If (The proportion of enterprises making payments for security or protection issues is Poor) and (The enterprises experience losses, average losses or any damages because of burglary is Poor) then (Security is Excellent);

7) If (The proportion of enterprises making payments for security or protection issues is Fair) and (The enterprises experience losses, average losses or any damages because of burglary is Fair) then (Security is Good);

8) If (The proportion of enterprises making payments for security or protection issues is Average) and (The enterprises experience losses, average losses or any damages because of burglary is Average) then (Security is Average);

9) If (The proportion of enterprises making payments for security or protection issues is Good) and (The enterprises experience losses, average losses or any damages because of burglary is Good) then (Security is Fair);

10) If (The proportion of enterprises making payments for security or protection issues is Excellent) and (The enterprises experience losses, average losses or any damages because of burglary is Excellent) then (Security is Poor);

11) If (The proportion of enterprises, which describes violence, theft, and other disorders as the main limitation is Poor) then (Security is Excellent);

12) If (The proportion of enterprises, which describes violence, theft, and other disorders as the main limitation is Fair) then (Security is Good);

13) If (The proportion of enterprises, which describes violence, theft, and other disorders as the main limitation is Average) then (Security is Average);

14) If (The proportion of enterprises, which describes violence, theft, and other disorders as the main limitation is Good) then (Security is Fair);

15) If (The proportion of enterprises, which describes violence, theft, and other disorders as the main limitation is Excellent) then (Security is Poor);

16) If (The enterprises make payments for security or protection, average security costs are Poor) and (The enterprises experience losses, average losses or any damages because of burglary is Poor) then (Security is Excellent);

17) If (The enterprises make payments for security or protection, average security costs are Fair) and (The enterprises experience losses, average losses or any damages because of burglary is Fair) then (Security is Good);

18) If (The enterprises make payments for security or protection, average security costs are Average) and (The enterprises experience losses, average losses or any damages because of burglary is Average) then (Security is Average);

19) If (The enterprises make payments for security or protection, average security costs are Good) and (The enterprises experience losses, average losses or any damages because of burglary is Good) then (Security is Fair);

20) If (The enterprises make payments for security or protection, average security costs are Excellent) and (The enterprises experience losses, average losses or any damages because of burglary is Excellent) then (Security is Poor);

21) If (The proportion of enterprises making payments for security or protection issues are Poor) and (Proportion of total product value, which was lost when delivered to the domestic markets, is Poor) then Security is Excellent); 
22) If (The proportion of enterprises making payments for security or protection issues are Fair) and (Proportion of total product value which was lost when delivered to the domestic markets is Fair) then Security is Good);

23) If (The proportion of enterprises making payments for security or protection issues are Average) and (Proportion of total product value, which was lost when delivered to the domestic markets, is Average) then Security is Average);

24) If (The proportion of enterprises making payments for security or protection issues are Good) and (Proportion of total product value, which was lost when delivered to the domestic markets is Good) then Security is Fair);

25) If (The proportion of enterprises making payments for security or protection issues are Excellent) and (Proportion of total product value, which was lost when delivered to the domestic markets is Excellent) then Security is Poor);

26) If (The proportion of enterprises making payments for security or protection issues are Poor) and (The proportion of enterprises, which describes violence, theft and other disorders as a main limitation is Poor) then (Security is Excellent);

27) (The proportion of enterprises making payments for security or protection issues are Fair) and (The proportion of enterprises, which describes violence, theft and other disorders as a main limitation is Fair) then (Security is Good);

28) (The proportion of enterprises making payments for security or protection issues are Average) and (The proportion of enterprises, which describes violence, theft and other disorders as a main limitation is Average) then (Security is Average);

29) (The proportion of enterprises making payments for security or protection issues are Good) and (The proportion of enterprises, which describes violence, theft and other disorders as a main limitation is Good) then (Security is Fair);

30) (The proportion of enterprises making payments for security or protection issues are Excellent) and (The proportion of enterprises, which describes violence, theft and other disorders as a main limitation is Excellent) then (Security is Poor).

Our output function will be also determined according to the minimax principle. The results of our calculations, according to which the output variable is equal to 87.7 (shows the level of "excellent") are presented in Figure 4:

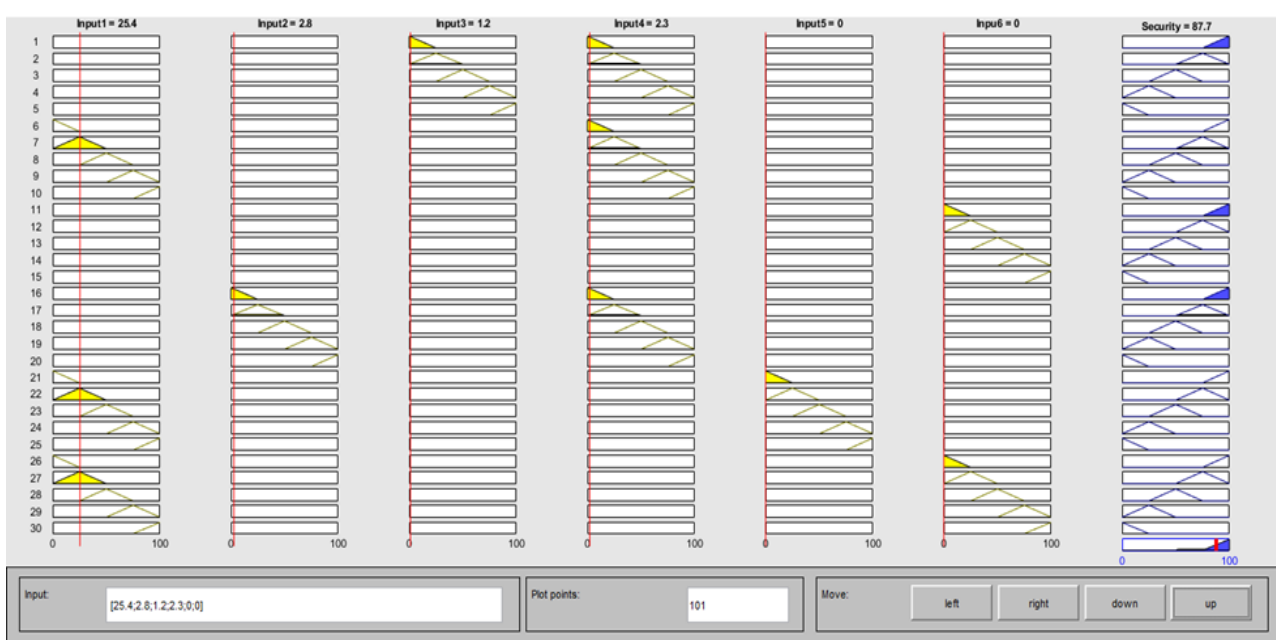

Fig. 4. The result calculations for term_Security_ 


\section{Conclusions}

Assessing the development of energy manufacturing enterprises in terms of trade, innovation and technology, and security makes it possible to identify the main problem areas of these sub-sectors. The results obtained allow us to state that, firstly, national trade has "weak" competitiveness, because enterprises have little interest in direct or indirect export. Secondly, innovation and technology based on the results of the study are presented as "fair" due to the lack of investment in national R\&D and a very small number of firms that are holders of internationally recognized quality certificates. However, in the security sector, an "excellent" result was obtained in Azerbaijan, since it is not considered as an obstacle to both production and logistics operations. Finally, all three indicators for the efficiency of energy manufacturing enterprises include important sub-indices for assessment, and a fuzzy tool allows identifying the results, combining qualitative and quantitative estimates.

The rationale for the application of the fuzzy sets' methods and the theory of fuzzy logic for assessing the effectiveness of the manufacturing enterprises' activities is given. World indicators with their sub-indices that impede the development of national manufacturing enterprises are analysed. The paper proposes a fuzzy production model and implements the process of fuzzy modelling of the rules sets by using the specialized Fuzzy Logic Toolbox of software package MATLAB. Fuzzy inference is realized on the base of the Mamdani algorithm. The sequence of actions when designing a fuzzy model for evaluating various indicators is determined. Input and output variables at the verbal level are defined, the sets of fuzzy rules are established for subsequent decision-making. The features of inference are considered and an analysis of the results of the study, confirming the feasibility of using fuzzy methods for solving estimation problems, is shown.

In this paper, three important aspects of manufacturing enterprises were evaluated. In further studies, this approach can be used in various sectors of the economy to reliably determine the expected results. The once-developed process of evaluating indicators and choosing the right methodology will help determine the strengths and weaknesses of the subject area in formulating basic assumptions and evaluating important criteria.

\section{References}

1. F.M. Martin, T. Ellen, A Practical Approach (1994)

2. A. Meier, W. Pedrycz, E. Portmann, Fuzzy Management Methods (2013)

3. L.A. Zadeh, Fuzzy Sets, Fuzzy Logic, and Fuzzy Systems, 394 (1996)

4. W. Pedrycz, Fuzzy Sets and Systems, 64(1), 21 (1994)

5. D. Shepherd, F. Shi, IFAC Proceedings Volumes, 31(16), 435 (1998)

6. T. Ramya, A.C. Kannan, R.S. Balasenthil, B.A. Bagirathi, Advanced Materials Research, 984 (2014)

7. P. Zlateva, L. Pashova, K. Stoyanov, D. Velev, 2nd International Conference on Education and Management Technology, 13 (2011)

8. S.Z. Iqbal, International Journal of Innovative Science and Research Technology, 3(8), 440 (2018)

9. M. Rubell, G. Lincy, J.C. Jessy, Expert Systems with Applications, 44, 13 (2016)

10. M. Stefanovic, S. Nestic, A. Djordjevic, D. Djurovic, I. Macuzic, D. Tadic, M. Gacic, Journal of Engineering Manufacture, 231(1), 15 (2015)

11. M. Shahjalal, S. Abeda, K.M. Nirmal, K. Khodadad, International Journal of Applied Economics and Finance, 6, 53 (2012)

12. Ch.Sh. Besta, A.K. Kastala, P.R. Ginuga, R.K. Vadeghar, IFAC Proceedings Volumes, 46(32), 349 (2013)

13. X.Q. Xu, Applied Mechanics and Materials, 494, 1306 (2014) 
14. A. Che Soh, L. Guan Rhung, H. Sarkan, International Journal on Computer Science and Engineering, 2(4), 924 (2010)

15. E.E. Zurek, D.J. Romero, H.D. Blanco, C.A. Gutiérrez. Rev. Univ. Medellín, 12(22), 109 (2013)

16. A. Uysal, S. Gokay, E. Soylu, T. Soylu, S. Çaşka, Measurement and Control, 52(7-8), 1137 (2019)

17. G. Buturac, D. Mikulić, P. Palić, Economic Research-Ekonomska Istraživanja, 32(1), 101 (2019)

18. M. Funke, R. Ruhwedel, Weltwirtschaftliches Archiv, 138, 97 (2002)

19. K. Karagöz, Procedia Economics and Finance, 38, 446 (2016)

20. Y. Simachev, M. Kuzyk, N. Zudin, Foresight And STI Governance, 10(4), 25 (2016)

21. A. Moeuf, S. Lamouri, R. Pellerin, S. Tamayo-Giraldo, E. Tobon-Valencia, R. Eburdy, International Journal of Production Research, 58(5), 1384 (2020)

22. M.R. Casals, M.A. Gil1, P. Gil, European Journal of Operational Research, 27(3), 371 (1986)

23. N. Kumar, Economic and Political Weekly, 20(35), M103 (2020)

24. Y. Zhao, S. von Delft, A.M. Thomas, T. Buck. Long Range Planning (2019)

25. Y. Lee, G.C. O'Connor, JAMS, 31, 241 (2003)

26. M. Daksa, M. Yismaw, S. Lemessa, J Innov Entrep, 7(6), (2018)

27. H. Wang, P. Liang, H. Li, R. Yang, Procedia Computer Science, 91, 122 (2016)

28. K. Blindab, A. Mangelsdorf, J. Pohlisch, International Journal of Production Economics, 198, 50 (2018)

29. A. Bisong, S.M. Rahman. International Journal of Network Security \& Its Applications, 3(1), 30 (2011)

30. J. Jang-Jaccard, S. Nepal, Journal of Computer and System Sciences, 80(5), 973 (2014)

31. S. Romanosky, Journal of Cybersecurity, 2(2), 121 (2016)

32. F. Jalilian, M. Vejdani, M. M. Alavijeh, F. Mostafavi, Avicenna J Neuro Psych Physio, 1(2), e24260 (2014)

33. C. Vignali. British Food Journal, 103(2), 97 (2001) 